\title{
A PRESENÇA MASCULINA EM CURSOS DE PEDAGOGIA
}

\section{MALE IN THE PRESENCE OF PEDAGOGY COURSES}

Gilson Xavier de Azevedo ${ }^{1}$

Resumo: Este artigo tem o objetivo de discutir a presença masculina em cursos de Pedagogia em uma perspectiva teórica. A pesquisa teve por objetivos específicos, o aprofundamento bibliográfico do tema, a constatação dos resultados analisados frente à realidade do curso de formação de pedagogos da referida unidade de ensino. O problema a ser investigado é se as fontes bibliográficas consultadas apontam para possíveis causas históricas de tal condição. O estudo se justifica pelo fato de que sendo do sexo masculino optei por este curso e constatando a ausência masculina neste me interessei por investigar a temática em minha própria condição. As hipóteses básicas foram que o problema tem raízes históricas, sociais ou mesmo familiares, dentre outras variantes. A metodologia empregada é a de uma pesquisa exploratória de caráter bibliográfico utilizando como técnica o estudo de caso. Os autores utilizados para tal fundamentação foram André (2002), Cardoso (2004), Carvalho (2010), Chamon (1996), Faria Filho (2005), Rabelo (2010). A metodologia empregada é a de um estudo exploratório de caráter bibliográfico. Esta pesquisa ainda analisou as dimensões gênero, trabalho e educação focando-se especificamente na dimensão: educação e trabalho. Acredita-se que com esse estudo pode-se aprofundar de forma cientifica a presença de homens na educação infantil e as razões da escassez desta.

Palavras-chave: Educação. Pedagogia. Gênero. Magistério. Educação Infantil.

Abstract: This article aims to discuss the male presence in Pedagogy courses in a theoretical perspective. The research had the specific objectives, the bibliographic deepening theme, examining the results analyzed against the reality of the training of pedagogues of that teaching unit. The problem to be investigated is whether the bibliographical sources consulted indicate possible historical causes of this condition. The study is justified by the fact that being male I chose this course and noting the absence from the male became interested in investigating the subject in my own condition. The basic assumptions were that the problem has historical, social or even family members, among other variants roots. The methodology is an exploratory survey of bibliographical technique using as a case study. The authors used for such reasons were André (2002), Cardoso (2004), Carvalho (2010), Chamon (1996 ), Faria Filho (2005), Rabelo (2010). The methodology is an exploratory study of bibliographical character. This research also examined the dimensions gender, labor and education focusing specifically on the dimension: education and work. It is believed that with this study can deepen scientific manner the presence of men in early childhood education and the reasons for this shortage.

Keywords: Education; Pedagogy; Gender; Child Education.

\section{INTRODUÇÃO}

Este estudo é apresentado com o objetivo de refletir o debate de gênero em um curso de Pedagogia, suas ausências e presenças em seu cotidiano. Mais especificamente a presença do sexo masculino no curso de Pedagogia da Universidade Estadual de Goiás, Unidade de Quirinópolis. O que de certa forma acaba impondo uma necessidade de se refletir também, sob alguns aspectos na educação infantil.

O presente artigo analisa as dimensões gênero, trabalho e educação onde se averigua indícios da presença masculina e possíveis apontamentos sobre os efeitos disso. Os objetivos específicos são: Fazer amplo levantamento bibliográfico sobre o tema em questão; Analisar a questão da presença masculina em cursos de pedagogia por meio das produções publicadas; Analisar a questão da presença masculina na educação infantil por meio das produções publicadas.

O tema Gênero no âmbito docente e universitário tem sido objeto de estudos diversos, sobremaneira no que se refere à presença do feminino nesse contexto e as suas variantes. Se for considerada a presença masculina em cursos de pedagogia ou mesmo no trabalho da docência em educação infantil, a incidência é mínima tanto sob

${ }^{1}$ Doutor em Ciências da Religião, Universidade Estadual de Goiás - gilson.azevedo@ueg.br 
o ponto de vista efetivo, quanto bibliográfico sobre o tema; menos ainda se estudam os efeitos desta presença.

Segundo André (2002):

[...] entre os alunos (moças e rapazes) e, até mesmo, entre as professoras, que consideram os rapazes inteligentes, mas desprovidos de jeito com as crianças. "Já em relação às moças, têm que ser meigas, gentis e atenciosas". Assim, uma possível justificativa para haver um percentual tão restrito de homens no curso de Pedagogia é o fato do magistério apresentar características que são tradicionalmente consideradas do sexo feminino (ANDRÉ, 2002, p. 194).

Diante de tais considerações, observa-se que o presente estudo poderá constituir-se de grande valia para docentes e discentes do curso a que se destina este projeto, de modo que possa servir de base para debates subjacentes no contexto em questão, fomentando não só a discussão focada na presença masculina na educação infantil e formação de professores, mas também a efetivação desta presença em tais contextos.

Em cursos de Pedagogia, é notória a ausência de alunos do sexo masculino. Sendo assim, a pesquisa apresenta como questões básicas a problemática do porque dessa ampla ausência a ser investigada e como se deu também historicamente a feminização do magistério.

A ausência do masculino na educação infantil e cursos de formação de professores no Brasil não responde por si só os problemas ora colocados nesse trabalho, de modo que se tenciona entender os elementos que ocasionaram essa ausência e a feminização do magistério, sendo considerados os fatores psicogenéticos, históricos, sociais e de representações de gêneros dentro do raio de material coletado.

A pesquisa se desenvolve na universidade de modo a fomentar investigações que consigam unir ensino, pesquisa e extensão em um mesmo mote de abrangência.

No caso desta pesquisa, optou-se pelo número de bibliografias vinculadas em artigos que se observou sobre a temática de se trabalhar inicialmente o tema na forma de uma pesquisa exploratória de caráter bibliográfico, já que não existem teorias constituídas sobre a presença de homens, tanto nos cursos de Pedagogia bem como na educação infantil na condição de professores.
Nesse sentido, conforme observa Barreto e Honorato:

Entende-se por planejamento da pesquisa a previsão racional de um evento, atividade, comportamento ou objeto que se pretende realizar a partir da perspectiva científica do pesquisador. Como previsão, deve ser entendida a explicitação do caráter antecipatório de ações e, como tal, atender a uma racionalidade informada pela perspectiva teórico metodológica da relação entre o sujeito e o objeto da pesquisa. A racionalidade deve-se manifestar através da vinculação estrutural entre o campo teórico e a realidade a ser pesquisada, além de atender ao critério da coerência interna. Mais ainda, devem prever rotinas de pesquisa que tornem possível atingirem-se os objetivos definidos, de tal forma que se consigam os melhores resultados com menor custo (BARRETO; HONORATO, 1998, p. 59).

Desse modo, trata-se de uma pesquisa exploratória que segundo Gil (2002, p. 41) tem como objetivo proporcionar maior familiaridade com o problema, com vistas a torná-lo mais explícito.

Pode envolver levantamento bibliográfico, entrevistas com pessoas experientes no problema pesquisado. Geralmente, assume a forma de pesquisa bibliográfica e estudo de caso.

Em relação aos procedimentos técnicos, pode-se classificar esta pesquisa como bibliográfica que ainda segundo Gil (2002) é desenvolvida com base em material já elaborado, constituído principalmente de livros e artigos científicos. Não é aconselhável que textos retirados da Internet constituam o arcabouço teórico do trabalho monográfico.

Lakatos e Marconi (1996) a respeito do procedimento monográfico aqui adotado, que este seria,

[...] um estudo sobre um tema específico ou particular de suficiente valor representativo e que obedece a rigorosa metodologia. Investiga determinado assunto não só em profundidade, mas em todos os seus ângulos e aspectos, dependendo dos fins a que se destina (LAKATOS; MARCONI, 2009, p. 151). 
Nesse aspecto, Gil (2002) considera: principal vantagem da pesquisa bibliográfica reside no fato de permitir ao investigador a cobertura de uma gama de fenômenos muito mais ampla do que aquela que poderia pesquisar diretamente. Essa vantagem torna-se particularmente importante quando o problema de pesquisa requer dados muito dispersos pelo espaço (GIL, 2002, p. 45).

O interesse pelo estudo surgiu do fato de que num curso como o que fiz com 114 acadêmicos, estão matriculadas apenas 03 pessoas do sexo masculino. Apenas em 2006 e 2010 houve uma turma do Curso de Pedagogia da UEG Quirinópolis, com mais de 03 homens matriculados. Conforme o exposto surgiu o desejo de se pesquisar o tema em questão, sendo que a metodologia adequada ao mesmo fora a exposta acima.

Dessa forma, espera-se com esse estudo, contribuir para o curso em qual estou em formação e demais cursos de pedagogia do país, de modo a permitir uma reflexão visando uma nova maneira de se pensar a educação infantil, a partir da questão da presença masculina em cursos de Pedagogia.

\section{DESENVOLVIMENTO}

O termo gênero constrói-se como instrumental teórico importante na análise das realidades sociais, desconstruindo leituras essencialistas e propondo pensar o como das desigualdades sociais se constituírem a partir das diferenças percebidas entre homens e mulheres. Logo, essas são fundamentalmente sociais, baseadas que são na diferença biológica entre os sexos, servindo como "verdades" para justificar discursivamente experiências de opressão. Neste capítulo pretende-se estudar as questões históricas de gênero, principalmente a feminização do magistério da educação infantil pelo viés do curso de Pedagogia.

\section{Gênero e história}

Ao debater a história do curso de Pedagogia, seja no Mundo ou no Brasil, sua gênese e desenvolvimento, é primordial enfatizar como as questões de gênero incidem neste processo e quais são suas implicações, ainda hoje, na organização dos cursos de formação de professores/as. Louro (1997) frisa ser necessário ressaltar o modo pelo qual os currículos desses cursos e o que esta história nos revela sobre as construções de gênero e sexualidade.

Em um processo de "mão-dupla", também é possibilitado pensar as implicações do curso de Pedagogia na constituição, confirmação, ou negação dos gêneros. Além disso, esse caminho nos provê de outras possibilidades e nos convida a problematizar as relações entre gênero, cultura e sociedade presentes na constituição e na caracterização do curso de Pedagogia como um espaço feminino (LOURO, 1997).

Relatar e descrever a história de um curso é dizer sobre um início, uma criação, um acontecimento e isso gera curiosidades, dúvidas. Acontecimento aqui é dado como a diferença que se constitui num jogo de forças, representando transformação e descontinuidade. Significa potencializar um dado para produzir "verdades", novas formas de regularidade. Assim, as reestruturações do curso de Pedagogia podem representar acontecimentos, uma vez que cada nova estruturação traz consigo outra regra, uma mudança.

Dizer da história do curso de Pedagogia é dizer sobre um campo construído e organizado por muitos sujeitos ao longo da sua trajetória, mas é também dizer de mim e de minha formação, como peça desse processo e agente deste. Uma história não linear que se organiza e reorganiza de acordo com os dispositivos instaurados em cada momento, representando, assim, um jogo de forças, como poderemos perceber durante este trabalho (LOURO, 1997).

Alguns desses dispositivos que merecem destaque são as Diretrizes Curriculares para o curso de Pedagogia que foram regulamentadas em 2006, dando ao curso uma nova aparência. No entanto, a discussão sobre sua área de atuação ocorre desde 1939, com a primeira regulamentação do curso de Pedagogia no Brasil que previa a formação do Bacharel em Pedagogia, conhecido como “técnico em Educação". Louro (1997) ainda destaca que, neste mesmo período, as mulheres começam a ocupar o espaço público e um destes lugares é a escola.

No título deste capítulo questiona-se se o curso é feminino. Para tanto, sabe-se que, historicamente, as mulheres são maioria no curso de Pedagogia e, por isso, a trajetória de construção social do magistério enquanto profissão pensada para mulheres necessita ser questionada. Na turma de Pedagogia na Universidade Estadual de Goiás Unidade de Quirinópolis do ano de 2010, por 
exemplo, composta por 30 estudantes, 26 eram mulheres e 4 homens, com isso este questionamento tem um porquê.

Em meados do século XXI, a maioria dos/as acadêmicos/as que ingressam na graduação em Pedagogia ainda são mulheres. No entanto, quando olhamos para a pós-graduação talvez essa prevalência se atenue. Homens de outras áreas se interessam pela Educação. O que isso está nos dizendo e por que o curso de Pedagogia, na sua formação inicial, mantém o predomínio feminino e, quando olhamos para a pós-graduação, encontramos um quadro diferente?

Estabelecidas essas relações, traz-se para o debate alguns aspectos da história do curso de Pedagogia: como este se relaciona à História da Educação, à História das Mulheres, às questões de gênero?

A história do curso de Pedagogia é permeada por uma grande questão sobre gênero, uma vez que o curso é caracterizado pela quase unânime presença feminina. Assim, considerar como se ligam a discussão de gênero e o percurso da Pedagogia pode-se sugerir quais identidades de gênero e sexualidade que as relações estabelecidas pelo e no currículo deste curso de formação vêm produzindo.

Diante disso, o que se pretende é "problematizar" como a atual estruturação do curso de Pedagogia se tornou o que é, e como se compôs e vem se compondo ao longo dos anos. A maneira como o curso de Pedagogia diz sobre a constituição dos gêneros e como os gêneros dizem sobre a organização e a história do curso são problemáticas que buscam colocar, sob suspeita, essas concepções e os processos cultural, social e histórico envolvidos nessa dinâmica para, ao mesmo tempo, pensarmos sobre nós mesmos.

Também se busca uma articulação entre os estudos de gênero e o campo da Educação, principalmente investindo nas perguntas, nos questionamentos, mais do que nas respostas. Acredita-se na força das perguntas para fazer mover e mudar.

\section{História da Pedagogia, história das mulheres e feminismo}

A partir de remanescentes históricos, percebe-se que a primeira metade do século XX foi marcada por um período de mudanças e de conflitos dentro e fora do Brasil. Dentre eles, podese citar como relevantes a I e II Guerras Mundiais, entre 1914 e 1945, que foram capazes de colocar as mulheres no mercado de trabalho em muitos países em função da necessidade de mão de obra em uma economia de guerra.

No mesmo período, no Brasil, ocorre a Intentona Comunista, nos anos 1930, que consistiu numa tentativa de golpe contra o governo de Getúlio Vargas. Assim, articulada pelo Partido Comunista Brasileiro, em nome da Aliança Nacional Libertadora, em novembro de 1935, teve como uma das protagonistas a comunista alemã Olga Prestes, designada a vir ao Brasil especialmente para preparar este movimento. As mulheres não ficam de fora desta história e é neste período que foi aprovado o direito de voto à mulher na Constituição de 1934 (art. 109), durante o Governo de Vargas. Esses são exemplos de acontecimentos importantes da História Mundial e do Brasil que colocaram as mulheres em outros lugares e, ao fazer isso, transformaram o lugar dos homens.

A Constituição de 1934 traz, também, contribuições importantes para o cenário educacional ao dedicar todo o seu capítulo II ao tema. Assim, ela estabelece que ao Governo Federal caberia "fixar o Plano Nacional de Educação, compreensivo do ensino de todos os graus e ramos, comuns e especializados; e coordenar e fiscalizar a sua execução, em todo o território do País" (art.150).

Pouco tempo depois de promulgada a Lei, o curso de Pedagogia tem a sua primeira regulamentação, em 1939, o que entrelaça a sua história ao percurso da Educação no país e à História das Mulheres. A constituição desse curso concomitante à busca pela participação feminina em outros campos que não o privado/doméstico e à expansão econômica - desenvolvimento industrial - corroboraram a inserção feminina no mercado de trabalho. Porém, com a presença das mulheres nesse novo espaço, algumas profissões foram vistas como continuidades dos serviços domésticos e, consequentemente, como trabalhos femininos; a Pedagogia se caracterizava como um desses afazeres femininos.

A profissão docente permitiu às mulheres o acesso a um dos espaços públicos anteriormente frequentados pelos homens. No entanto, essa profissão vai ser representada como similar ao trabalho no lar: o cuidar das crianças. Essa concepção é utilizada para naturalizar/reforçar o magistério, especialmente das séries iniciais, como uma profissão feminina. Assim, retomo, como modelo, a poetisa Adélia Prado (s.d.) para 
exemplificar as mulheres de que se fala. Adélia é uma poetisa e faz uma ligação de suas poesias com as instituições.

Dessa forma, as mulheres se constituem maioria no espaço do magistério. Conforme (LOURO, 1997, p. 88) "elas organizam e ocupa o espaço, elas são as professoras; a atividade escolar é marcada pelo cuidado, pela vigilância e pela educação, tarefa tradicionalmente feminina". As práticas se constituem como "naturais" e é para elas que se deve atentar. Por isso, é necessário problematizar gênero e docência e quais as continuidades e rupturas de gênero nos cursos de formação de professores/as.

Nesse processo de feminização do magistério ocorre também a transferência dos predicados do lar - cuidado, carinho, amor, dedicação, vocação - para esse campo. Essa atividade é considerada uma continuidade da educação primária do lar e esses atributos vão constituindo o feminino. Assim, conhecer essas relações possibilitará compreender, mais adiante, algumas categorias analisadas neste trabalho. É fato, no que se refere a gênero, como discute Carvalho (2010), que os homens, quando permanecem no sistema educacional, especialmente nas séries iniciais, dificilmente atuam nas salas de aula. Homens que adotam o magistério como profissão em grande maioria, direcionam sua carreira para outros cargos e abandonam o espaço das salas. Com isso, é importante problematizar até que ponto eles se direcionam ou são direcionados, para tal. Os discursos são produzidos em torno do magistério infantil como o não lugar do masculino. Ainda de acordo com Carvalho (2010), os professores homens elegem como última opção o magistério.

De acordo com Silva (2011), as principais conclusões de estudos recentes vão à direção de que os homens optam tardiamente pela carreira de magistério, muitas vezes tendo percorrido outras opções profissionais; e a autora menciona ainda que tendem a sofrer maiores pressões tanto em direção a outras ocupações, quanto no sentido da ascensão na carreira, quase sempre para deixar a sala de aula e ocupar cargos administrativos; e em geral fazem planos para o futuro mais amplos que as mulheres, envolvendo mais frequentemente atividades fora de sala de aula.

Buscando vincular a história de criação do curso de Pedagogia às questões de gênero que a permeiam, são poucos os trabalhos que apresentam as temáticas de constituição do curso e, ao mesmo tempo, suas relações com a temática de gênero. A maioria dos trabalhos que discutem a constituição do curso se prende às questões legislativas e a períodos de mudanças em sua organização (VIANNA, 2010).

Já os que se debruçam sobre as questões de gênero privilegiam a discussão sobre a feminização da atividade docente na educação infantil e nos anos iniciais do ensino fundamental, como podemos citar Rabelo e Martins (2010); Almeida (1996) e Vianna (2010), ou sobre a necessidade da discussão das relações de gênero no espaço escolar (Louro e Meyer, 2010; Louro, 1997).

Mas vale ressaltar que as questões de gênero e sexualidade vêm ganhando lugar nas análises e pesquisas educacionais. Assim, os estudiosos têm procurado relacionar os estudos de gênero e o campo da Educação; todavia esse é um processo em curso.

O esforço de diálogo entre a História, a História do curso de Pedagogia e as questões de gênero, não tem a intenção de aprofundar ou julgar os estudos realizados nessa área de pesquisa. Procura-se situar o leitor na discussão por vir, ressaltando as possíveis relações, como aborda Foucault (2005), sobre a noção de história e documento.

Uma história que rompe com as continuidades, adotando-as como objeto de descrição e como questão metodológica que "organiza, recorta, distribui, distingue o que é pertinente do que não é, identifica elementos, define unidades, descreve relações" (FOUCAULT, 2005, p. 7).

O curso de Pedagogia surge com a necessidade de formação de professores/as em nível superior, em substituição às escolas normais. A primeira regulamentação do curso de Pedagogia no Brasil, segundo Chaves (1981), ocorre em 1939, prevendo a formação do Bacharel em Pedagogia, conhecido como "técnico em Educação".

Ressalta-se que esse período é marcado por transformações no campo político, econômico e social que afetam a relação público/privado, representada aqui pelo homem e pela mulher, respectivamente.

É o momento de industrialização do Brasil, do início da Segunda Grande Guerra, de aumento das cidades em detrimento do meio rural, enfim, há mudanças nos níveis econômicos e sociais que modificam a relação das mulheres com o mundo do trabalho, com o doméstico e com os 
homens. Com tais transformações, as mulheres adentram a esfera pública.

$\mathrm{Na}$ Educação, esse tempo é marcado pela $4^{a}$ Constituição, em 1946, sob o Governo de Eurico Gaspar Dutra, que promove a criação de institutos de pesquisa, de preferência junto aos institutos de ensino superior (art.174, parágrafo único). Fortes pressões conservadoras participaram do processo de discussão das propostas educacionais.

Em 1949, é lançado, por uma das mulheres mais expressivas no que se refere à luta feminina, Simone de Beauvoir (1967), o Segundo Sexo, que teve influência nos estudos feministas e de gênero. Beauvoir, ainda hoje, continua sendo lembrada nas academias como referência aos estudos feministas e, nesse clássico, faz um alerta às mulheres:

As mulheres de hoje estão destronando o mito da feminilidade; começam a afirmar concretamente sua independência; mas não é sem dificuldade que conseguem viver integralmente sua condição de ser humano.Educadas por mulheres, no seio de um mundo feminino, seu destino normal é o casamento que ainda as subordina praticamente ao homem; o prestígio viril está longe de se ter apagado: assenta ainda em sólidas bases econômicas e sociais. É, pois necessário estudar com cuidado o destino tradicional da mulher. Como a mulher faz o aprendizado de sua condição, como a sente, em que universo se acha encerrada, que evasões lhe são permitidas, eis o que procurarei descrever. Só então poderemos compreender que problemas se apresentam às mulheres que, herdeiras de um pesado passado, se esforçam por forjar um futuro novo (BEAUVOIR, 1967, p. 8).

Assim, a presença feminina nos espaços públicos vai aumentando gradualmente. $\mathrm{O}$ movimento feminista tem o seu marco na década de 60 ao apresentar, como principais reivindicações, a busca pela igualdade e procurar, como sugere Beauvoir na passagem citada, destronar o mito da feminilidade. Outra pauta dessas mulheres é a discussão sobre a Educação, reivindicando a escolaridade. Serem reconhecidas como sujeitos da história e da ciência foi em que mais investiram as primeiras manifestantes do movimento feminista (SANTOS, 2009).

Já de acordo com Scott (1990), o uso do termo "gênero" é um aspecto que poderia ser chamado de procura de uma legitimidade acadêmica pelos estudos feministas nos anos 1980:

Esses usos descritivos do gênero foram utilizados pelos (as) historiadores (as), na maioria dos casos, para mapear um novo terreno. $\mathrm{Na}$ medida em que os (as) historiadores (as) sociais se voltaram para novos temas de estudo, o gênero dizia respeito apenas a temas como as mulheres, as crianças, as famílias e as ideologias de gênero. Em outros termos, esse uso do gênero só se refere aos domínios - tanto estruturais quanto ideológicos - que implicam em relações entre os sexos (SCOTT, 1990, p. 3).

Com o avanço das lutas contemporâneas dos movimentos sociais de mulheres feministas nos anos 1970, os estudos de gênero têm início para referirem-se à organização social da relação entre os sexos, negando o determinismo biológico no uso dos termos como "sexo" ou "diferença sexual".

O termo "gênero" surge com o papel político de questionar e debater sobre a ausência das mulheres na história, o silenciamento sobre suas participações como sujeitas e, consequentemente, como participantes nas pesquisas científicas até então predominantes (LOURO, 1997).

No seu uso mais contemporâneo, o "gênero" parece ter surgido primeiro entre as feministas americanas que queriam insistir na qualidade fundamentalmente social das distinções baseadas no sexo. "O gênero" sublinhava também o aspecto relacional das definições normativas de feminilidade" (SCOTT, 1990, p. 1).

Analisar a forma como esses temas são construídos socialmente torna o conceito de gênero uma importante ferramenta. Este é um desafio teórico, como defende Scott (1990). Numa segunda fase do feminismo, a luta das mulheres centrava esforços para problematizar uma revisão da história como não neutra. Em uma sociedade excludente, ocupar o espaço escolar foi uma forma de brigar pelo reconhecimento. Assim, de acordo com Scott (1990), as lutas posteriores e atuais necessitam dedicar-se à valorização do trabalho feminino, uma vez que ocupar as instituições 
escolares e demais espaços frequentados pelos homens não garantiu a igualdade de direitos:

[...] fará emergir uma história que oferecerá novas perspectivas às velhas questões (sobre, por exemplo, como é imposto o poder político, qual é o impacto da guerra sobre a sociedade), redefinirá as antigas questões em termos novos (introduzindo, por exemplo, considerações sobre a família e a sexualidade no estudo da economia e da guerra), tornará as mulheres visíveis como participantes ativas e estabelecerá uma distância analítica entre a linguagem aparentemente fixada do passado e nossa própria terminologia. Além do mais, essa nova história abrirá possibilidades para a reflexão sobre as estratégias políticas feministas atuais e o futuro (utópico), porque ela sugere que o gênero tem que ser redefinido e reestruturado em conjunção com uma visão de igualdade política e social que inclui não (SCOTT, 1990, p. 35).

Há que se perceber na citação acima, algumas indagações me chamam a atenção tem a história do curso de Pedagogia participado da construção das relações de gênero e o que sua história relata. A importância de se conceber a Pedagogia não apenas como campo de habilidades ou técnicas educacionais. Para tanto, o conhecer a história desse curso significa analisá-la como um modo de produção cultural de saber, em que o poder e o sentido são empregados na construção e no preparo do conhecimento. Como construção, portanto, essa história pode ser também desconstruída.

Voltando à narrativa histórica tem-se que, após a regulamentação do curso de Pedagogia, em 1939, este só sofrerá alterações com a criação da Lei de Diretrizes e Bases da Educação Nacional (LDB), em atendimento à Lei n..$^{\circ}$ 4.024/61 (LDB). Com isso, o curso de Bacharelado para a formação do Pedagogo se mantém (parecer CFE 251/62) e se regulamentam as Licenciaturas (parecer CFE 292/62). Já o parecer CFE 252/69 aboliu a diferença entre Bacharelado e Licenciatura, mas manteve a formação de especialistas nas várias habilitações. Essas significam as primeiras mudanças no fluxo da história.
Segundo Chaves (1981), as iniciativas de reconsiderar ou propor novas bases para o curso de Pedagogia e Licenciaturas surgem na segunda metade da década de 1970. Iniciativas que envolviam organismos oficiais e entidades independentes de educadores, tais como o Ministério de Educação, o Conselho Federal de Educação e o Comitê Pró-formação do educador, atual Associação Nacional para a Formação de Profissionais da Educação (ANFOPE, 2004).

Entidades essas que, ainda hoje, analisam e discutem o perfil do curso de Pedagogia, disputando entre seus "regimes de verdade" a configuração do perfil de profissional a ser formado e quais são as identidades projetadas por essas instituições.

Nesse mesmo tempo, por volta dos anos 1975, tem-se na História do feminismo a chamada Segunda Onda. A preocupação, nesse período, do movimento, no que se refere à Educação, centravase na necessidade das instituições se transformarem e organizarem "currículos que refletissem, de forma equilibrada, tanto a experiência masculina, quanto a feminina".

Dessa forma, a demanda se estende para além do acesso à Educação, "preocupavam-se em desenvolver formas de ensino que refletissem os valores feministas e que pudessem formar um contraponto às práticas pedagógicas tradicionais. Práticas essas consideradas como expressão de valores masculinos e patriarcais" (SILVA, 2009, p. 94-96).

A partir dos anos 1980, destaca-se o desempenho do movimento de replanejamento dos cursos de formação do educador pela democratização da sociedade. O movimento feminista brasileiro ganha força com uma atuação mais especializada, com uma perspectiva mais técnica e profissional.

Dentro da tendência à especialização, desenvolve-se, também, a pesquisa acadêmica sobre a mulher; o que "implicou sempre em uma postura crítica na formulação de propostas para a formação de professores/as dos diversos níveis de ensino".

Essa atividade perdura até hoje na Associação Nacional para a Formação de Profissionais da Educação (ANFOPE, 2004, p. 8).

As mulheres já eram presentes nas escolas e, concomitante a isso, o movimento feminista teve forte impacto no país, nos anos 70, como descreve Sarti: 
Embora uma confluência de fatores tenha contribuído para a eclosão do feminismo brasileiro nos anos 70 - como o impacto do feminismo internacional e mudanças efetivas na situação da mulher no país a partir dos anos 60, que punham em questão a tradicional hierarquia de gênero -, o feminismo no Brasil surge como consequência da resistência das mulheres à ditadura militar, depois da derrota $\mathrm{da}$ luta armada e no sentido da elaboração política e pessoal desta derrota (SARTI, 2010, p. 3).

Em meio a essa efervescência as lutas e as demandas colocadas em pauta pelo movimento das mulheres buscarão desnaturalizar as diferenças percebidas entre os sexos e isso se reflete no magistério.

A escolha profissional docente, as influências que as mulheres sofrem e a visão dos atrativos que estas teriam para o magistério passaram a ser questionadas pelas feministas. As estudiosas buscaram contestar as histórias que divulgavam que as profissões consideradas movidas pela "emoção" seriam próprias das mulheres e as ligadas à "inteligência" seriam patrimônio exclusivo dos homens.

As mudanças que ocorreram na sociedade, nos anos 1970, principalmente no processo de trabalho com a introdução de novas tecnologias, passaram a exigir a formação de um trabalhador mais flexível, eficiente e polivalente, tendo isso reflexo, também, no curso de Pedagogia. Essa transformação implica numa reformulação do sistema educacional, visando qualificar melhor as pessoas para enfrentarem um mundo mais competitivo, mais afinado com o mercado.

A reorganização social exige uma reorganização dos corpos, como discute Foucault (1988). Quando se lança uma nova regra, novas formas de ser ou de estar socialmente exige-se uma nova postura dos sujeitos e a disciplinarização dos corpos é uma das possibilidades de garantir tal ordenamento.

Assim, o discurso é renovado e, com ele, novas formas de controle apreendem os sujeitos. Pode-se perceber esse processo no conflito existente entre as duas vertentes do feminismo no Brasil representadas abaixo.

Conflitos que dividem pensamentos e ações em prol de objetivos próximos. Essas mudanças ocorrem no mesmo período em que Sarti (2010) considera haver duas tendências fortes no movimento feminista nacional:

Parece haver um consenso em torno da existência de duas tendências principais dentro da corrente feminista do movimento de mulheres nos anos 70. A primeira, mais voltada para a atuação pública das mulheres, investindo em sua organização política, concentrando-se principalmente nas questões relativas ao trabalho, ao direito e à redistribuição de poder entre os sexos. Foi a corrente que posteriormente buscou impactar as políticas públicas, utilizando os canais institucionais criados dentro do próprio Estado, no período da redemocratização dos anos 80. A outra vertente preocupase, sobretudo com o terreno fluido da subjetividade, com as relações interpessoais, tendo no mundo privado seu campo privilegiado. Manifestou-se principalmente através de grupos de estudos, de reflexão e de convivência. Nestes grupos ressoava a ideia de que o “pessoal é político (SARTI, 2010, p. 7).

Os conflitos teóricos e práticos podem possibilitar o avanço de um grupo, assim como desenvolver um trabalho, como este trabalho, é tomar para si um conjunto de saberes e problematizá-los. Para isso, torna-se importante desconstruir até mesmo o que se descreve para ir além do limite do pensamento. Quando existe a possibilidade de discussões e questionamentos variados, mais se pode explorar de um tema.

Isso foi possível no embate entre as militantes do movimento nacional feminista, como descreve Louro (1997). Assim, as militantes do meio acadêmico procuravam levar para as universidades e escolas as questões que as mobilizavam. Já a outra vertente do movimento centrava forças na atuação pública e nas conquistas práticas. Dessa forma, as tensões teóricas do movimento residiam na ideia de que existiria "uma identidade única entre mulheres, contra a da existência de múltiplas identidades" (SOIHET, 1997 , p. 277).

As contribuições do movimento feminista vão além da construção de uma nova história da mulher, pois colaboram para o desenvolvimento de outra forma de análise 
histórica. Como discute Soihet (1997), o movimento feminista se inicia "expandindo os limites da história". A história do movimento feminista e a discussão posta aqui, sobre a história do curso de Pedagogia e suas relações com gênero, inscrevem-se ou podem se inscrever nessa dinâmica.

As mudanças da realidade relatadas anteriormente vêm ocorrendo aos poucos, por meio das lutas desses sujeitos "menores". Sujeitos que têm procurado ocupar os diversos espaços que lhes são de direito. As mulheres representam parte desses grupos minoritários, por isso relacionar suas conquistas e lutas à história do curso de Pedagogia ajudará a analisar as transformações frente às demais discriminações existentes nessas instâncias. Compreender como se dá a supervalorização de um grupo e a desvalorização de outro, ou como um discurso é reestruturado é o que se procurou fazer ao estudar a História do curso de Pedagogia.

\section{A feminização do magistério}

A partir da primeira guerra mundial, as mulheres, cada vez mais tem ganhado espaço nos mais variados mercados de trabalho; durante as guerras, são elas que assumem os lugares de seus maridos e na ausência definitiva desses, elas tornam-se os esteios familiares, de modo que algumas profissões acabaram se tornando específicas delas até bem pouco tempo. É o caso da educação infantil, onde tanto em cursos de formação quanto na prática da profissão em sala de aula, creches e pré-escolas, as mulheres se mostram maioria.

Este cenário vem mudando muito lentamente e não se trata de uma nova forma de luta de classes, mas de ajustes e de uma maior procura pelo campo educacional infantil por parte de homens. Segundo Faria Filho:

Já no início do século $\mathrm{XX}$, as mulheres vão se tornando maioria no exercício da profissão docente, sobretudo como decorrência dos baixos salários, sendo esta uma razão que explica o processo de evasão de professores e professoras, que atinge sobremaneira os docentes do sexo masculino. Mesmo depois de mais de 100 anos, a evasão dos homens da profissão docente continua sendo justificada pelos baixos salários e pelo desprestígio da profissão, embora recentes estudos mostrem outros fatores (FARIA FILHO, 2005, p. 3).
Pode-se apontar segundo Faria filho (2005) quatro causas disso: alterações no mercado de trabalho favorecendo o trabalho fabril para homens; a escolarização de meninas; o protagonismo feminino na educação como extensão do lar e ocupação do lugar da mãe que foi para o chão das fábricas e a feminizarão da escola primária.

Segundo Faria filho (2005), pode-se chegar a algumas conclusões sobre o exposto:

1) Que praticamente em todo o. Brasil o magistério se torna uma ocupação majoritariamente feminina entre os finais do século XIX e início do século XX; 2) Que as razões evocadas para explicar este fenômeno são muito semelhantes em todos os trabalhos e são, na maioria das vezes, mais afirmadas do que demonstradas; [..] 4) Que não há um único trabalho que enfoque especificamente a questão da presença masculina no magistério primário [...] (FARIA FILHO, 2005, p. 4).

De acordo com Chamon (1996), os homens abandonavam o magistério para ocuparem profissões mais rentáveis, além disso, as mulheres notaram historicamente que a tarefa de ensinar abria-lhes uma brecha de estarem em contato com a vida pública sem serem difamadas recorda Probst (2012, p. 5).

Se por um lado a docência é hoje essencialmente um trabalho de mulheres, isso não implica que seja apenas delas esta função. A primeira imagem que surge então é justamente as de que homens heterossexuais ou não, dificilmente desenvolveriam aptidões para lidar com o trato que se deve aos pequenos.

Atualmente, debates sobre crise da masculinidade, mudanças no comportamento masculino, transformações em seus papéis sociais, surgimento de um novo homem têm gradativamente ganhado espaços $\mathrm{e}$ contornos nos discursos produzidos pela academia, pela literatura, pela mídia e por outros espaços sociais. Igualmente têm povoado as mais diversas esferas do cotidiano da vida social: as brincadeiras, as conversas informais, as instituições, as 
músicas, os relacionamentos afetivos e amorosos (CARDOSO, 2004, p. 1).

Os contornos diferentes que a vida masculina e o trabalho escolar tem ganhado faz com que a presença do homem nesses espaços não seja apenas en passant, ao contrário disso, tem-se hoje bons e crescentes números. Contudo, para Cardoso (2004, p. 2): "Para se pensar a questão dos professores homens da educação de crianças no Brasil de hoje, torna-se importante apresentar ainda outro dado: cerca de $94 \%$ do total do corpo docente é composto por mulheres". Ou seja, a imagem socialmente constituída hoje é de que escola infantil é serviço de mulher, homem, apenas como o porteiro ou proprietário no caso das particulares.

Apesar do exposto, nota-se que características tradicionalmente tidas como femininas constituem não só a representação de professoras como a própria representação da docência na qual:

[...] as professoras, mas também os professores homens amam os seus alunos, e é através da concretização desse afeto em gestos concretos que se efetua a redenção desses últimos. A imagem do professor missionário ('que missão é essa que espalha o conhecimento, propaga o saber e gera ideias! '), que cumpre uma missão do amor, [...] comparável à missão religiosa pela ênfase ao amor (SILVEIRA, 2008, p. 3-4).

A identidade docente é frequentemente tratada como algo não problemático e as imagens e representações mais aceitas são naturalizadas. Esta é uma visão estática que despersonaliza a docência e mantém sobre sua imagem uma visão perene, imutável, sempre associada à vocação e acima das mudanças.

[...] estes estereótipos tradicionais continuam fortemente incorporados nas crianças de hoje (algumas das quais serão os docentes de amanhã) e nos docentes de hoje (todos que foram as crianças de ontem), a despeito do mito comum de que os métodos de ensino nos dias atuais são radicalmente diferentes (WEBER E MITCHELL, 1996, p. 112).
Britzman (1991) relaciona identidade profissional e esses estereótipos, mostrando que o professorado cai na armadilha das imagens, ao admitir que significados socialmente construídos se transformem em algo inato e natural, essencialista.

Nesse sentido, Fonseca (2011, p. 21) questiona: "Quais os discursos e representações de gênero e masculinidade que surgem na escola a partir da presença do professor homem dos anos iniciais, e de que forma estes discursos contribuem para sua subjetivação?".

Pode-se então entrever que:

A formação, portanto, não significa dar um mesmo formato a sujeitos distintos, mas significa sensibilizar cada um a assumir sua própria possibilidade como educador. Para assumir tal possibilidade, por vezes é necessário 'combater o que já se é', ainda que esse esforço não esteja inserido em nenhum propósito emancipador. A ideia de formação precisaria ser entendida como uma 'vontade de Arte para poder mostrar sua dimensão estética ou poética. 'A formação tem uma relação com a invenção, com a capacidade criativa dos seres humanos, não é uma busca do autoconhecimento, da arrogância de quem se constituiu individualmente, mas tem relação com as experiências pelas quais passamos e como elas nos tocam' (HARDT, 2006, p. 7-8).

Além de um direito a esta desconstrução da imagem apenas feminina no ensino fundamental, os homens têm a real possibilidade. Fonseca (2011, p. 37) completa dizendo que: "Personagens-professores-homens que se constroem, subjetivamente, num processo de identificação com o ser homem e com o ser professor. Compreendê-los como personagem significa dotar-lhes de história, de infância, de passado, de caráter".

A construção histórica desses indivíduos se dá, portanto no desenvolvimento do processo de inserção destes, independente da opção sexual, de modo a tornarem-se o que a profissão exige, ou seja, que sejam cuidadores de crianças e desenvolvedores destas. Rabelo (2010) nesse contexto tem a acrescer à discussão que:

Contudo, frente aos nossos dados, que mostram a possibilidade de escolha profissional dos professores motivada por 
desejo e realização (apesar das dificuldades), podemos dizer que a extrema ambiguidade do ato de ensinar e da presença tanto dos homens quanto das mulheres no magistério está no gosto/amor pela profissão; na incorporação deste desejo às possibilidades da sua realização; na associação das vicissitudes da vida com a paixão pela docência; na luta, apesar do descaso e do baixo estatuto; no investimento do seu "suor", das suas "lágrimas", mas também dos seus "sorrisos", "gostos" e "encantos" nesta profissão. Falar de sentimentos em uma profissão tão feminina é demonstrar que todas as escolhas, formas de atuação (movidas pela razão ou pela emoção) precisam ser legitimadas e que estas atitudes e profissões não são masculinas nem femininas, mas humanas (RABELO, 2010, p. 286).

A educação frente ao exposto se realizada por homens tem o mesmo princípio e risco de sucesso que a promovida pelo outro sexo, de modo que o que se vai expor a seguir é um aprofundamento da sombra constituída historicamente pela presença feminina na educação infantil.

\section{Mulheres, educação e maternagem}

É paradoxal pensar na pouca capacidade intelectual atribuída historicamente às mulheres, e na sua grande responsabilidade para manutenção da família e educação dos filhos. Excluídas da educação formal até o século XVIII, aproximadamente, quando o advento da burguesia provocou profundas mudanças na realidade e sentimentos da família, as mulheres eram educadas em casa, para que impregnadas do pensamento moral e dos bons costumes, exercessem a sua missão/destino: a maternidade.

Para o exercício deste papel social, a formação nos conventos que eram o primeiro espaço para a educação formal feminina, era considerada suficiente. Lá as meninas aprendiam os valores morais, costumes, fé católica e conhecimentos específicos para que lidasse adequadamente com a casa, os filhos, o marido. Como analisa Passos (1995, p. 121) " [...] as mulheres deviam receber uma educação firme, capaz de prepará-las para ocuparem-se da casa e dos filhos".

As primeiras escolas para mulheres tiveram fundamental importância para a manutenção da cultura e pensamento dominante, possibilitando pensar numa mulher educável, pronta para moldar-se ao imaginário de uma mulher ideal - a mãe - dona de casa. $\mathrm{Na}$ escola, a possibilidade de ler, escrever, dominar conhecimentos para desempenhar bem seu papel doméstico e ao mesmo tempo formar novos cidadãos.

Por seu caráter de cuidado, atenção, carinho, idoneidade e proximidade com a maternagem, a atividade docente passou a ser então uma forma legitimada de inserção das mulheres no universo do trabalho e na ocupação do espaço público.

Com o passar dos tempos com as grandes transformações políticas e econômicas que passava o Brasil no século XIX, a função de educadora profissional se delineava, pois através dela as mulheres foram autorizadas a exercer uma carreira no espaço público e a ampliar seus estudos para melhor desempenhar a função que lhes foi confiada ainda que fosse com baixos salários.

Assim reflete Almeida (1998) sobre a instrução feminina no século XIX:

Mantida dentro de certos limites, a instrução feminina não ameaçaria os lares, a família e o homem. Essa educação, que a princípio e de acordo com a tradição portuguesa, fora negada sob pretexto de que o conhecimento e sabedoria eram prejudiciais e desnecessários a sua frágil constituição física e intelectual, acabou por revelar-se desejável a partir do momento em que a mulher passou a ser vista, na sociedade da época, como a principal mantenedora da família e da pátria (ALMEIDA, 1998, p. 33).

Com os discursos de modernização da sociedade e da mulher "talhada" para o ensino do magistério, discutível associação à maternidade e ao essencialismo favorecia sua entrada e permanência neste campo profissional. A mulherprofessora foi vista como sinônimo de ternura, cuidado, docilidade e, não necessariamente de competência. Já o homem-professor é visto como profissional revestido de autoridade, de poder, de competência. 
O início do século XX marca um novo período para a educação feminina, fruto das reivindicações e discussões feministas em diferentes partes do mundo e principalmente na Europa. Ainda que dirigidas por homens, as mulheres passam a ocupar também hospitais, universidades e outros setores da sociedade marcadamente masculinos.

Com a crescente industrialização e modernização do país, a inserção feminina em diferentes espaços públicos e a produção acadêmica se avoluma, abrindo espaço para a visibilização e a legitimação do lugar que a mulher ocupa na sociedade com o pesado trabalho doméstico e a dupla jornada de trabalho.

Mulheres e homens, sujeitos diferenciados em constante relação cultural e historicamente construída tendo por base a assimetria e a hierarquização, advinda da forma como as mulheres e os homens tiveram acesso aos processos, conteúdos e espaços educacionais. Historicamente, homens e mulheres receberam criação, educação e orientação diferenciada, numa constante afirmação das diferenças e do espaço que cada um/uma pode e deve ocupar na dinâmica social.

\section{Mulheres em sala de aula}

O projeto constitucional brasileiro de 1879 modificou a maneira como estava organizado o ensino primário na corte, porém a grande alteração que trouxe se referia à liberdade para a criação de escolas em todos os níveis e, quanto ao estudo, não mais obrigatório o ensino da religião para os alunos não católicos. De tal forma, as instituições de ensino seriam vistoriadas quanto aos aspectos referentes à moralidade e higiene.

Outra mudança promovida por esta lei foi a de ter permitido a coeducação dos sexos nas escolas primárias, ou seja, as escolas para o sexo feminino receberiam alunos até 10 anos de idade, estando o seu ensino a cargo das professoras. Os argumentos que defendiam a coeducação eram os mais variados, podendo ser observados discursos que apoiavam a medida por ser mais seguro para as meninas, pois transitariam pelas ruas acompanhadas de irmãos. Em outros casos, observa-se a preferência da mulher para o magistério primário devido às suas características dóceis.

No entanto, é necessário ressaltar a não unanimidade destes discursos, os quais estiveram presentes ao longo deste século, inclusive no interior da Escola Normal da Corte. Esta instituição, fundada em 1880, destinava formar professores de ambos os sexos para a instrução primária. O seu currículo compreenderia as matérias necessárias aos professores para atuar na instrução primária, sendo pensado a fim de ultrapassar os conhecimentos dessas escolas e com especial atenção à metodologia de ensino.

Uma maior presença feminina nas escolas primárias pode também ser observada a partir da década de 1970 do século passado, gerando a necessidade da inserção de mulheres neste ofício. Nesse sentido, o aumento gradual de mulheres no quadro docente, a procura pela Escola Normal, dentre outros fatores modificou as representações acerca desta ocupação. Estes números apontam para um processo que vinha se afirmando no final deste século em diversas províncias do Império, o da feminização do magistério primário.

Nesse sentido, segundo os autores, pode ser observada a construção da ideia de que as mulheres deveriam entrar para o magistério e, uma representação que ligava o magistério primário à maternidade e, portanto, a uma função feminina.

Contudo, como pesquisas apontam é importante observar que este processo não se deu de forma homogêniea, não possuindo uma causa única capaz de explicar este fenômeno, uma vez que homens e mulheres resistiram e se apropriaram de normas e regras frente aos seus interesses. Assim, esta temática deve ser analisada a partir dos jogos de ralações que a permeiam, pois as mulheres tiveram uma participação, com maior ou menor grau, no processo de feminização do magistério primário e, havendo também, no interior deste grupo, posições conflitantes quanto à melhor forma de inserção neste ofício.

\section{Trajetórias de professores homens no magistério dos anos iniciais}

Segundo Eugênio (2008), pode-se observar que nas cidades do interior da Bahia é comum encontrar um número considerável de homens exercendo a docência na educação das crianças. Algumas pesquisas realizadas em outros contextos também têm chamado atenção para este ponto. Carvalho (2004), ao apresentar os resultados de sua investigação realizada numa escola da periferia de São Paulo, aponta para o processo de constituição profissional e as práticas pedagógicas de um dos educadores, o único professor homem atuando nos anos iniciais do ensino fundamental. Para Carvalho (2004, p. 182) 
a relação deste professor com o magistério diferia em muito das relações observadas em relação às demais professoras. Diferente destas, neste professor as ideias de cuidado não se evidenciava, tampouco questões relacionadas à vocação. "O magistério era um trabalho como outro qualquer e a relação com as crianças".

$O$ autor Cardoso (2007) investigou o processo de constituição identitária de professores homens no trabalho com crianças de 6 a 8 anos na rede Municipal de Belo Horizonte. $O$ autor identifica 9 professores em situações e atividades de trabalho e constata que somente um deles estava em sala de aula. Os outros exerciam outras funções nas escolas, como coordenador de turno, atuação em laboratório de ciências. Também Carvalho (2007) em sua pesquisa aponta para o fato de que é comum os professores que trabalham nos anos iniciais almejarem assumir o posto de diretor como forma de sair da sala de aula.

O pesquisador Sayão (2005) investigou o trabalho de professores na educação infantil, buscando compreender como esses homens se constituem como docentes num espaço tido socialmente como tipicamente feminino.

Já Silva (2006) investigou o trabalho de homens na docência dos anos iniciais. $O$ autor investiga as vivências corporais de três professores de um município do interior mineiro na lida cotidiana com seus alunos. Valendo - se da história oral e de observações do trabalho desses professores, Silva reconstrói suas histórias de vida e aponta como as masculinidades desses sujeitos vão se construindo na sua relação com os alunos e os demais sujeitos do espaço escolar.

Silva (2006), após percorrer pelas histórias de vidas desses sujeitos professores, conclui que:

[...] a estética corporal dos professores do modo como é por cada um experimentada, passa pelos desafios de romper com barreiras individuais que cada um carregou (e/ou ainda carrega) em si, devido a sua subjetividade e experiências, como também pelo social, na direção do que propõe Mauss (1974) e Rodrigues (1983), dentre outros, que apontam as normatizações sociais que tentam moldar o corpo, em culturas distintas, através de sistemas de classificação (SILVA, 2006, p. 326).
Baseado nas investigações e nos dados encontrados no texto entende-se que ainda há necessidade de mais investigações que objetivem compreender aspectos referentes à docência na educação infantil e anos iniciais do ensino fundamental como elemento importante para o entendimento da construção da profissionalidade. Isso tudo precisa atentar-se para as inter-relações de raça e gênero que perpassam o entendimento do processo de constituição identitária desses homens professores.

\section{CONSIDERAÇÕES FINAIS}

Em alguns momentos citados no primeiro capítulo deste trabalho sugere-se entender que a História do curso de Pedagogia se entrelaça à História das Mulheres. Assim, a profissão docente permite às mulheres o acesso a um espaço público anteriormente frequentado apenas por homens.

Dessa forma, esta profissão foi representada como semelhante ao trabalho no lar e reproduções, como estas foram utilizadas para naturalizar/reforçar o magistério, especialmente da educação infantil e dos anos iniciais do ensino fundamental, como uma profissão feminina. Contudo, a história do movimento feminista e a discussão posta, aqui, sobre a História do curso de Pedagogia e suas relações com gênero se inscrevem ou podem se inscrever numa nova dinâmica de análise.

Nessa perspectiva, pode-se ainda frisar, no tocante a essa questão as palavras de Badinter em seu polêmico livro Um amor conquistado - o mito do amor materno, onde afirma claramente estar convencida de que "o amor de mãe existe desde a origem dos tempos, mas reconhece que esse amor não está presente em todas as mulheres e diz não acreditar que a espécie humana dependa dele para sobreviver: qualquer pessoa que não a mãe (o pai, a ama, etc.) pode "maternar" uma criança" (BADINTER, 1985, p. 17).

Evidencia-se claramente nas palavras da autora, que o sexo masculino também pode maternar, desde que reúna atributos para isso.

Reforça-se ainda que nas respostas coletadas, os aspectos elencados pela escolha do curso de Pedagogia foram muito pelo lado pessoal, não existindo, a partir da opinião dos participantes, nenhum outro fator que merecesse atenção diferenciada.

Nota-se que, dos três alunos egressos, nenhum atua na área de formação, onde os 
respondentes justificaram existir outras oportunidades melhores que os fizeram optarem pelas funções que exercem hoje. Dos três participantes egressos, um atua no magistério de nível superior, outro está licenciado da função e último exerce uma função de gestão educacional na cidade onde reside.

No caso deste último respondente vale citar as palavras de Marília Pinto de Carvalho (1998) sobre as perspectivas de carreira e razões de escolha ocupacional por homens que optam pela carreira do magistério apontam que, "quase sempre, há o desejo por parte desses docentes em deixar a sala de aula para ocuparem cargos de gestão".

Neste caso denotam-se fatores sociais e econômicos que justificam a não atuação no magistério na educação infantil e anos iniciais.

Quanto à visão da sociedade em torno da participação masculina, seja nos cursos de Pedagogia ou no exercício da docência na educação infantil e anos iniciais do ensino fundamental, já demonstra traços de aceitação, ainda prevalece pelo exposto nos questionários, algumas evidências da tendência cultural à participação feminina neste tipo de função na sociedade.

"Ainda assim, ao contrário do que reza a tradição cultural e linguística, a "maternagem" não tem sexo" (BADINTER 1993, p. 178).

Mesmo que seja notório e ou perceptível nas sociedades ocidentais a diminuição da cultura machista e aceitação da presença masculina em funções até então tidas como femininas e os homens tenham assumido, de maneira menos machista, as atribuições relacionadas aos afazeres domésticos, ao cuidado e à educação dos filhos, há um olhar enviesado para aqueles poucos educadores que assumem, profissionalmente, a docência das crianças pequenas.

\section{REFERÊNCIAS}

ALMEIDA, Jane Soares. Mulheres na Escola: Algumas reflexões sobre o magistério feminino. Cadernos de Pesquisa. São Paulo, n.96, p. 71-78, fev.1996.

ANDRÉ, Marli. (Org). Formação de professores no Brasil, 1990-1998. Brasília: MEC/INEP/Comped, 2002. (Série Estado do Conhecimento $n^{\circ} 6$ ).

ANFOPE. Associação Nacional pela formação dos profissionais da educação (2004). Políticas Públicas de Formação dos Profissionais da
Educação: Desafios para as Instituições de Ensino Superior. Documento Final do XII Encontro Nacional, Brasília - DF, 2004.

BADINTER, Elisabeth. Um amor conquistado: o mito do amor materno. Rio de Janeiro: Nova Fronteira, 1985.

BARRETO, Alcyrus Vieira Pinto; HONORATO, Cezar de Freitas. Manual de sobrevivência na selva acadêmica. Rio de Janeiro: Objeto Direto, 1998.

BEAVOUIR, Simone de. O segundo sexo. 1967 Disponível em: <http://brasil.indymedia.org/media/2008/ 01//409680.pdf. Acesso em: 12 de Junho de 2013.

BOURDIEU, P; PASSERON, J. C. A reprodução. Elementos para uma teoria do sistema de ensino. Rio de Janeiro: Francisco Alves, 2001.

BRASIL. Conselho federal de Educação. Parecer CFE 251/62.

BRASIL. Conselho federal de Educação. Parecer CFE 292/62.

BRASIL. Constituição Federal. 1934.

BRASIL. Lei de Diretrizes e Bases da Educação Nacional. 4.024/61.

BRITZMAN, Deborah. Curiosidade, sexualidade e Curriculo. In: LOURO, Guacira Lopes (ORG.) O corpo educado: pedagogias da sexualidade. $2^{\mathrm{a}}$ ed. Belo Horizonte: Autêntica, 1991.

CARDOSO, Frederico Assis. A identidade de professores homens na docência com crianças: homens fora do lugar? 2004. $154 \mathrm{f}$. Dissertação (Mestrado em Educação) Faculdade de Educação, Universidade Federal de Minas Gerais, Belo Horizonte, 2004.

CARVALHO, Marília Pinto de. No coração da sala de aula: gênero e trabalho docente nas séries iniciais. São Paulo: Xamã, 2004.

CARVALHO, Marilia Pinto. Vozes Masculinas Numa Profissão Feminina: o que têm a dizer os professores/as? Setembro de 2010. Disponível em: $<$ http://lasa.international.pitt.edu/LASA98 
/PintodeCarvalho.pdf >. Acesso em: Agosto de 2013.

CHAMON, Magda Lúcia. Relações de gênero e a trajetória de feminização do magistério em Minas Gerais (1830-1930) Belo Horizonte, MG, 1996. FaE/UFMG (Tese de doutorado).

CHAVES, Eduardo O.C. O Curso de Pedagogia. IN: Cadernos CEDES, A formação do Educador em Debate: 2. Ano 1, n.2 - 1981. Construção de sua identidade (1909-2002). Disponível em: <http://www.fae.ufmg.br/portalmineiro/p ortal. Acesso em: 18/09/2013.

EUGÊENIO, Benedito G. Processos de constituição profissional de professores homens nas séries iniciais. Práxis Educacional, v.4, n.5, 2008.

FARIA FILHO, Luciano Mendes de e outros. $A$ bistória da feminização do magistério no Brasil: balanço e perspectivas de pesquisa. In: PEIXOTO, Ana Maria Casasanta (Org.). A escola e seus atores. Belo Horizonte: Autêntica. 2005, p. 53-87.

FONSECA, Thomaz Spartacus Martins. Quem é o professor homem dos anos iniciais? Discursos, representações e relações de gênero. 2011. Disponível em: <http://www.ufff.br/ppge/files/2011/07/ Disserta\%C3\%A7\%C3\%A3o_Thomaz_Spa rtacus.pdf>. Acesso em: 05 Out. 2013.

FOUCAULT, Michel. Microfísica do poder. $11^{\mathrm{a}} \mathrm{ed}$. Rio de Janeiro: Graal, 2005.

FOUCAULT, Michel. Vigiar e punir. Petrópolis: Vozes, 1988.

GIL, A.C. Métodos e técnicas de pesquisa social. São Paulo: Atlas, 2002.

HARDT, Lúcia Schneider. Formação de professores: as travessias do cuidado de si. Anped - 2008.

LOURO, Guacira Lopes; MEYER, Dagmar Estermann. Gênero e educação. Rev. Estud. Fem., Florianópolis, v. 9, n. 2, 2001. Disponível em: $<$ http://www.scielo.br/scielo.php?script $=$ s ci_arttext\&pid $=$ S0104-26X2001000200010 \&lng $=$ en\&nrm $=$ iso $>$. Acesso em: 05 Out. 2013.
PASSOS, Elizete Silva. A educaşão das virgens. Revista Brasileira de Estudos Pedagógicos, Brasília, v .75, n. 179/180/18 1, jan./dez. 1994. p.301-306.

PRADO, Adélia. Releituras: resumo biográfico e bibliográfico. s.d. Disponível em: $<$ http://www.releituras.com/aprado_bio.as p>. Acesso em: 10 Ago.2013.

PROBST, Carlos Guilherme. Identidade e Gênero na Pedagogia. Ijui, RS. Ed. UNIJUI, 2001.

RABELO, Amanda Oliveira; MARTINS, António Maria. A mulher no magistério brasileiro: um histórico sobre a feminização do magistério. Diaponível em: www.faced.ufu.br/colubhe06/anais/arquiv os/556AmandaO.Rabelo.pdf. Acesso: 05 de outubro de 2013.

SANTOS, Raphaela Sousa. Entre Lembranças e Silêncios - memórias de mulheres alunas de EJA. Dissertação de mestrado: UFJF. Juiz de Fora. Universidade Federal de Juiz de ForaMG. mimeo 2009. Disponível em: $<$ http://www.bdtd.ufff.br/tde_busca/arqui vo.php?codArquivo=590. Acesso em: $24 \mathrm{de}$ outubro de 2013.

SARTI, Cynthia A. O início do feminismo sob a ditadura no Brasil: o que ficou escondido. Disponível em:

$<$ http://lasa.international.pitt.edu/LASA98 /Sarti.pdf. Acesso em: 20/09/2013.

SAYÃO, Déborah. Relações de gênero e trabalho docente na educação infantil: um estudo de professores em creche. 2005. 272 f. Tese (Doutorado em Educação) - Centro de Ciências da Educação, Universidade Federal de Santa Catarina, Florianópolis, 2005.

SCOTT, Joan. Gênero: uma categoria útil de análise histórica. Educação e realidade. Porto Alegre: v. $16, \mathrm{n}^{\circ}$. 2, p. 5-22. julho/dezembro de 1990.

SILVA, K. RIBEIRO, M.G.M. Dez. Anos de Avaliação da Universidade Brasileira: o caso da UFV. Relatório de Pesquisa: Iniciação Científica/PIBIC/CNPq/UFV. Viçosa: Universidade Federal de Viçosa. mimeo 2009. 
SILVA, Mirian P. Memórias de professore(a)s sobre sexualidade e o curriculo como narrativa. Tese (Doutorado em Educação). Faculdade de Educação, UNICAMP, Campinas, 2006.

SILVEIRA, Rosa Maria H. Ela ensina com amor e carinho, mas toda enferada, danada da vida: representações de professora na literatura infantil. Educação \& Realidade, v.22, n.2, p.149-161, jul./dez. 1997.

SOIHET, Rachel, (1974). Bertha Lutz e a ascensão social da mulher. Mestrado em História. Departamento de História. Instituto de
Ciências Humanas e Filosofia da Universidade Federal Fluminense.

VIANNA, Cláudia Pereira. O sexo e o gênero da docência. 2001 Disponível em: $<$ http://www.scielo.br/pdf/cpa/n1718/n17a03.pdf. Acesso em: 16 de agosto de 2013. 192

WEBER, Sandra; MITCHELL, Claudia. Using Drawings to Interrogate Professional Identity and the Popular Culture of Teaching. In: GOODSON, Ivor; HARGREAVES, Andy. (ed.) Teachers' Professional Lives. London/ Washington, DC. : Falmer Press, 1996. 